\title{
Assessment of plasmapheresis
}

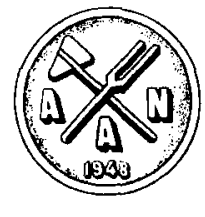

\author{
Report of the Therapeutics and Technology Assessment Subcommittee of the \\ American Academy of Neurology
}

In this article, we have assessed the value of plasmapheresis as a tool for treatment of patients with neurologic disorders. We chose to use the more common term "plasmapheresis," which technically means removal of plasma only, for the proper term, "plasma exchange," which technically refers to both removal of plasma and its replacement. In the literature, these terms are used interchangeably.

Using the Medline search, including the "back 90" and "back 85 " backfiles, we batched the terms "plasmapheresis" and "neurologic disease (exploded)" from 1985 to 1995 , which yielded a total of 544 articles. The titles of these articles were scanned and those thought relevant to the assessment were reviewed in their entirety. In addition, a Medline search was made that cross-referenced the terms "plasmapheresis" and "neurologic diseases (exploded)" with "randomized controlled trial" (publication type). We excluded articles about plasmapheresis used to treat stroke. This led to only six citations. We also relied upon the NIH Consensus Conference of 1986 on Plasmapheresis and Neurologic Disease. ${ }^{1}$ We spoke with experts in the field, and several individuals wrote directly to the AAN to express their opinions.

Plasmapheresis. Mechanics. Plasmapheresis (PP) is the removal of whole blood from the patient, its separation by machine into component parts, and then the return of certain of those components to the patient. The PP described in this assessment is the separation of the formed elements from the liquid elements in blood, the reconstitution of the formed elements with another plasma source (either natural or artificial), and the reinfusion of that plasma source along with the patient's own formed elements. On occasion, although rarely used in neurologic disorders, this procedure can be adjusted to remove white cells, platelets, or immunoglobulins alone.

The literature refers to both discontinuous- and continuous-flow machines. In discontinuous-flow machines-the older and now less common type-whole blood is removed from the patient, separated and reconstituted, and then the removal of whole blood stopped and the patient rein- fused with the reconstituted solution; that is, either blood goes out or the reconstitute goes in, but both do not occur simultaneously. The newer and more efficient continuousflow machines remove whole blood from one intravenous site while simultaneously and continuously returning the reconstituted elements through another intravenous site. Continuous-flow machines shorten the time of PP. If venous access is limited, most continuous-flow machines can be operated in a discontinuous manner with one venous access.

Replacement solutions. Usually 1 to $1 \frac{1}{2}$ plasma volumes are removed at each procedure. This requires replacement with albumin or plasma protein fractions in combination with sterile saline. There is no risk of disease transmission if blood products other than albumin and plasma protein fractions are avoided.

Anticoagulants. Regional anticoagulation with citrate is usually used. While this may result in transient hypocalcemia, it is less risky than using systemic anticoagulation with heparin.

Presumed mechanisms. A variety of possible mechanisms for the actions of therapeutic PP has been proposed, including removal of antibody, removal of alloantibody, removal of immune complexes, removal of a monoclonal protein, removal of toxin or cytokine(s), replenishment of a specific plasma factor, and, lastly, the placebo effect. For most neurologic diseases, PP presumably removes pathogenic antibodies from the immunoglobulin fraction of serum. Only in myasthenia gravis (MG), however, has this presumption been shown, ${ }^{2,3}$ in that patient improvement is associated with a drop in antibody titers as a result of PP. In most of the other diseases discussed below, the pathogenic antibodies are not identified or, if identified, have not been measured in a rigorous fashion. It should be noted, however, that other mechanisms may exist. Indeed, PP can be looked upon as a "blunderbuss" that removes all the nonformed elements in plasma, including immunoglobulins, cytokines, and other serum factors, in a nonspecific fashion. The specific factor whose removal is crucial in therapeutically successful PP is thus not specifically known. Surprisingly, systematic data on the effects of PP in controls are scarce; that is, little is known about the effects of PP 
Table Summary of the American Academy of Neurology assessment of plasmapheresis

\begin{tabular}{|c|c|c|c|}
\hline Disease & Definitions & Quality & Strength \\
\hline $\begin{array}{l}\text { Guillain-Barré } \\
\text { syndrome-severe }\end{array}$ & Established & Class I & pe A \\
\hline $\begin{array}{c}\text { Chronic inflammatory } \\
\text { demyelinating } \\
\text { polyneuropathy }\end{array}$ & Established & Class I & Type A \\
\hline \multicolumn{4}{|l|}{$\begin{array}{l}\text { Polyneuropathy with } \\
\text { monoclonal } \\
\text { gammopathies of } \\
\text { undetermined } \\
\text { significance: }\end{array}$} \\
\hline IgG/IgA & Established & Class I & Type A \\
\hline $\operatorname{IgM}$ & Investigational & Class I & \\
\hline $\begin{array}{l}\text { Myasthenia gravis- } \\
\text { Pre-op preparation } \\
\text { and crisis }\end{array}$ & Established & Class III & Type C \\
\hline $\begin{array}{c}\text { Lambert-Eaton } \\
\text { myasthenic } \\
\text { syndrome }\end{array}$ & Possibly useful & Class II/III & \\
\hline Refsum's disease & Investigational & Class III & \\
\hline $\begin{array}{l}\text { Acquired } \\
\text { neuromyotonia }\end{array}$ & Investigational & Class III & \\
\hline Stiff-man syndrome & Investigational & Class III & \\
\hline $\begin{array}{l}\text { Cryoglobulinemic } \\
\text { polyneuropathy }\end{array}$ & Investigational & Class III & \\
\hline $\begin{array}{l}\text { Central nervous system } \\
\text { systemic lupus }\end{array}$ & Investigational & Class IlI & \\
\hline $\begin{array}{l}\text { Acute disseminated } \\
\text { encephalomyelitis }\end{array}$ & Investigational & & \\
\hline Multiple sclerosis & Possibly useful & & \\
\hline
\end{tabular}

on serum levels of the variety of factors now known to be important in immune reactions.

Cost. The cost of PP varies considerably, typically $\$ 1,000$ to $\$ 2,000$ per procedure. Thus, a five-session course of $P P$ can cost between $\$ 5,000$ and $\$ 10,000$.

Safety profile. In experienced hands, PP is extremely safe. Although hypotension, dizziness, and perioral tingling (hypocalcemia) may occur either during or following PP, most of these reactions are rapidly recognized and reversed, and are rarely serious. ${ }^{4}$ There is a risk of infection from the intravenous manipulations, but this has proven to be minimal. Probably the greatest risk to patients are the procedures necessary to ensure adequate venous access, in particular the placement of the central venous catheters, which are associated with a low but definite risk of pneumothorax, thrombosis, and infection. Deaths from PP have been reported, but have generally been related to preexisting illness.

Diseases. Guillain-Barré syndrome. Three randomized controlled trials ${ }^{5-7}$ have shown that PP improves the outcome of patients with severe Guillain-Barré syndrome (GBS). In these studies, entry was limited to those patients with GBS severe enough to prevent independent walking. $\mathrm{PP}$ is considered established for this population with severe GBS, based on Class $I$ evidence and a Type $A$ recom- mendation. Whether PP should be used in patients with GBS who are less severely affected is unknown at this time.

Chronic inflammatory demyelinating polyradiculoneuropathy. A randomized controlled trial performed by Dyck et al. ${ }^{8}$ showed that a significant proportion of patients with chronic inflammatory demyelinating polyneuropathy improved following PP. Thus, PP is a useful modality of therapy in this group of patients, who may also benefit from oral prednisone and intravenous human immune globulin, as shown in randomized controlled trials. ${ }^{9-11}$ Which of these therapies is best will depend on a number of factors, as has been reviewed recently. ${ }^{10} \mathrm{PP}$ is considered established for this disorder, with minimal Class $I$ evidence and a Type $A$ recommendation.

Polyneuropathy associated with monoclonal gammopathies of undetermined significance. A randornized controlled trial ${ }^{10}$ has shown that patients with polyneuropathy associated with IgA and IgG monoclonal gammopathies of undetermined significance (MGUS) improve following therapy with PP. Those with IgM MGUS and polyneuropathy did not improve. The patients entering this study were heterogeneous and included those with both demyelinating and axonal polyneuropathies. Patients in the IgM MGUS group may have included those with anti-myelinassociated glycoprotein antibodies. Because of continuing controversy concerning the exact relationship of the monoclonal protein to the neuropathy, treatment decisions in these patients remain individualized. PP may be considered possibly useful for these disorders. For those with IgA and IgG, Class $I$ evidence would indicate that PP is established.

Myasthenia gravis. Although no controlled clinical trials have been performed of PP in MG, a sufficient number of case series, as well as the experiences of experts, have been reported ${ }^{1,2,12,13}$ to establish clearly the value of PP in $\mathrm{MG}$. The two most common indications for PP in myasthenia are preoperative preparation and treatment of myasthenic crisis. PP would be considered established for $\mathrm{MG}$ for these indications, based on Class III evidence, Type C. PP may occasionally be used in the chronic long-term therapy of patients with myasthenia, ${ }^{14}$ although most authorities prefer immunosuppressant drugs. ${ }^{15}$

Lambert-Eaton myasthenic syndrome. While no controlled trials exist on the use of PP in the Lambert-Eaton myasthenic syndrome (LEMS), a case series ${ }^{16}$ has suggested a benefit. The rationale is similar to that in myasthenia; that is, patient strength should be improved by the removal of the pathogenic antibody to the voltage-gated calcium channel. In most cases, patients are treated longterm with a combination of corticosteroids and immunosuppressant drugs. ${ }^{17} \mathrm{PP}$ would be considered promising for LEMS based on Class $I I$ and III evidence, Type $C$.

Multiple sclerosis. Khatri et al. ${ }^{18}$ studied 54 patients with chronic-progressive multiple sclerosis (MS) who, in addition to receiving oral low-dose cyclophosphamide and prednisone, were randomized to receive either true $\mathrm{PP}$ or sham PP for 20 weeks. This study showed that patients in the true-PP arm were more likely to improve (14/26 at 5 months and 11/26 at 12 months) than were those in the sham-PP arm (8/29 at 5 months and 5/29 at 11 months).

Weiner et al. ${ }^{19}$ studied 116 patients with acute exacerbations of MS randomized to receive either $\mathrm{PP}$ or sham $\mathrm{PP}$, 
both in association with ongoing ACTH and oral cyclophosphamide, for 24 months. No overall differences emerged among these patients, even when analyzing for subtypes of MS, such as relapsing-remitting or chronic-progressive.

The Canadian Cooperative Multiple Sclerosis Study Group $^{20}$ compared four treatments in patients with progressive MS: (1) intravenous cyclophosphamide and oral prednisone, (2) daily oral cyclophosphamide and alternateday prednisone, (3) weekly $\mathrm{PP}$, or (4) placebo medication and sham PP. All patients were followed for at least 12 months, with a mean of 30 months, and no differences were found among the groups in the primary analysis of rates of treatment failure. Additionally, no differences were detected in the proportions of patients who improved among the groups during the course of this study. In the study ${ }^{18}$ showing an improvement in the true- vs sham-PP patients, all patients were on concomitant immunosuppressant drug therapy. In the only study in which PP was compared to sham PP and to immunosuppressant drug therapy, no clear benefit was shown for PP alone.

A recent report by Rodriguez et al. ${ }^{21}$ suggests that in certain individuals with acute fulminant MS, PP may be of benefit, without the use of concomitant immunosuppressive therapy. The exact role of PP in the care and treatment of patients with multiple sclerosis remains unclear. While selected MS patients may benefit from this therapy, they are also likely to be on concomitant immunosuppressant drug treatments, so that the true effect of $P P$ is difficult to determine. Therapeutic PP may have a role in selected cases of fulminant MS, and a double-blind NIHfunded trial is currently under way. Based on these studies, PP for the treatment of MS must be considered promising, based on some Class I evidence.

Miscellaneous disorders. PP may have a role in Refsum's disease in lowering the levels of phytanic acid, ${ }^{22}$ but the exact role of PP in relationship to dietary restriction of phytanic acid remains to be elucidated. Single reports have suggested that PP may be of use in acute disseminated encephalomyelitis, ${ }^{23}$ in acquired neuromyotonia, ${ }^{24}$ in stiffman syndrome, ${ }^{25}$ and in central nervous system systemic lupus. ${ }^{26}$ In addition, multiple case series ${ }^{2732}$ have suggested that PP may be of use in cryoglobulinemic polyneuropathy. The use of PP in Refsum's disease, acute disseminated encephalomyelitis, acquired neuromyotonia, stiffman syndrome, central nervous system systemic lupus, and cryoglobulinemic polyneuropathy, must be considered investigational, based on Class III evidence.

Amyotrophic lateral sclerosis. No evidence suggests that PP has any role in the treatment of patients with amyotrophic lateral sclerosis (Consensus Conference, 1986).

Paraneoplastic neurologic syndromes with circulating antibodies. Based on the case series by Graus et al., ${ }^{33}$ no evidence suggests that PP has a role in treating patients with neurologic paraneoplastic syndromes with circulating autoantibodies.

Summary. Based on the review of the literature, therapeutic PP has a definite role in the treatment of patients with GBS, CIDP, polyneuropathies associated with MGUS, MG, and LEMS (table). PP may have a role in treating patients with Refsum's disease, acquired neuromyotonia, stiff-man syndrome, cryoglobulinemic polyneuropathy, CNS-SLE, ADEM, and MS, but these decisions should be made on a case-by-case basis. PP has no role in treating patients with ALS or paraneoplastic syndromes with circulating autoantibodies.

\section{Acknowledgments}

The Therapeutics and Technology Subcommittee would like to thank David R. Cornblath, MD, for his work as Senior Author on this technology assessment, as well as those who served as Panel Members: Hayden G. Braine, MD; P.J. Dyck, MD; Jerry R. Mendell, MD; Moses Rodriguez, MD; Allan H. Ropper, $\mathrm{MD}$; and Jerry S. Wolinsky, MD.

Therapeutics and Technology Assessment Subcommittee: John H. Ferguson, MD, Chair; Paul H. Altrocchi, MD; Mitchell Brin, MD; Robert S. Goldman, MD; Michael Goldstein, MD; Douglas S. Goodin, MD; Philip B. Gorelick, MD; Daniel F. Hanley, MD; Dale J. Lange, MD; Anne Marie Marini, MD, PhD; Marc R. Nuwer, MD, PhD; E. Steven Roach, MD, Stanley van den Noort, MD.

Note. This statement is provided as an educational service of the American Academy of Neurology. It is based on an assessment of current scientific and clinical information. It is not intended to include all possible proper methods of care for a particular neurologic problem or all legitimate criteria for choosing to use a specific procedure. Neither is it intended to exclude any reasonable alternative methodologies. The AAN recognizes that specific patient care decisions are the prerogative of the patient and the physician caring for the patient, based on all of the circumstances involved.

\section{Definitions \\ Safety:}

A judgment of the acceptability of risk in a specified situation; e.g., for a given medical problem, by a provider with specified training, at a specified type of facility.

\section{Effectiveness:}

Producing a desired effect under conditions of actual use.

\section{Established:}

Accepted as appropriate by the practicing medical community for the given indication in the specified patient population.

\section{Possibly useful:}

Given current knowledge, this technology appears to be appropriate for the given indication in the specified patient population. As more experience and long-term follow-up are accumulated, this interim rating will change.

\section{Investigational:}

Evidence insufficient to determine appropriateness, warrants further study. Use of this technology for given indication in the specified patient population should be confined largely to research protocols.

\section{Doubtful:}

Given current knowledge, this technology appears to be inappropriate for the given indication in the specified patient population. As more experience and long-term 
follow-up are accumulated, this interim rating will change.

\section{Unacceptable:}

Regarded by the practicing medical community as inappropriate for the given indication in the specified patient population.

\section{Suggested Quality of Evidence Ratings:}

\section{Class I:}

Evidence provided by one or more well-designed, randomized, controlled, clinical trials.

\section{Class II:}

Evidence provided by one or more well-designed clinical studies such as case control, cohort studies, etc.

\section{Class III:}

Evidence provided by expert opinion, nonrandomized historical controls, or case reports of one or more.

\section{Suggested Strength of Recommendations Ratings:}

Type A:

Strong positive recommendation, based on Class I evidence, or, when circumstances preclude randomized clinical trials, overwhelming Class II evidence.

\section{Type B:}

Positive recommendation, based on Class II evidence.

\section{Type C:}

Positive recommendation, based on strong consensus of Class III evidence.

\section{Type D:}

Negative recommendation, based on inconclusive or conflicting Class II evidence.

\section{Type E:}

Negative recommendation, based on evidence of ineffectiveness or lack of efficacy, based on Class II or Class I evidence.

\section{References}

1. Consensus Conference. The utility of therapeutic plasmapheresis for neurological disorders. JAMA 1986;256:13331337.

2. Dau PC, Lindstrom JM, Cassel CK, Denys EH, Shev EE, Spitler LE. Plasmapheresis and immunosuppressive drug therapy in myasthenia gravis. N Engl J Med 1977;297:11341140.

3. Newsom-Davis J, Pinching AJ, Wilson SG. Function of circulating antibody to acetylcholine receptor in myasthenia gravis: investigation by plasma exchange. Neurology 1978;28:266.

4. Rodnitzky RL, Goeken JA. Complications of plasma exchange in neurological patients. Arch Neurol 1982;39:350-353.

5. Osterman PO, Lundemo G, Pirskanen R, Fagius J, Pihlstedt $P$, Siden A. Beneficial effects of plasma exchange in acute inflammatory polyradiculoneuropathy. Lancet 1984;2:12961298.

6. Guillain-Barré Study Group. Plasmapheresis and acute Guillain-Barré syndrome. Neurology 1985;35:1096-1104.

7. French Cooperative Group on Plasma Exchange in GuillainBarré Syndrome. Efficacy of plasma exchange in GuillainBarré syndrome: role of replacement fluids. Ann Neurol 1987; 22:753-761

8. Dyck PJ, Daube J, O'Brien P, et al. Plasma exchange in chronic inflammatory demyelinating polyradiculoneuropathy. N Engl J Med 1986;314:461-465.

9. Dyck PJ, O'Brien PC, Oviatt KF, et al. Prednisone improves chronic inflammatory demyelinating polyradiculoneuropathy more than no treatment. Ann Neurol 1982;11:136-141.

10. Dyck PJ, Litchy WJ, Kratz KM, et al. A plasma exchange versus immune globulin infusion trial in chronic inflammatory demyelinating polyradiculoneuropathy. Ann Neurol 1994; $36: 838-845$

11. Hahn AF, Bolton CF, Vandervoort P, Feasby TE, Zochodne D. Intravenous immunoglobulin treatment (IvIg) in chronic in- flammatory demyelinating polyneuropathy (CIDP): a doubleblind, placebo-controlled, crossover study [abstract]. Neurology 1995;45(suppl 4):A416.

12. Pinching AJ, Peters DK, Newsom-Davis JN. Remission of myasthenia gravis following plasma exchange. Lancet 1976;2: 1373-1376.

13. Lisak RP, Abramsky O, Schotland DL. Plasmapheresis in the treatment of myasthenia gravis: preliminary study in 21 patients. In: Dau PC, ed. Plasmapheresis and the immunobiology of myasthenia gravis. Boston: Houghton Mifflin, 1979: $209-215$.

14. Newsom-Davis J, Vincent A, Wilson SG, Ward CD. Long-term effects of repeated plasma exchange in myasthenia gravis. Lancet 1979;1:464-468.

15. Chaudhry V, Cornblath DR. Immunosuppressive therapy for myasthenia gravis. In: Lisak RP, ed. Handbook of myasthenia gravis. New York: Marcel Dekker, 1994:341-374.

16. Newsom-Davis J, Murray NMF. Plasma exchange and immunosuppressive drug treatment in the Lambert-Eaton myasthenic syndrome. Neurology 1984;34:480-485.

17. McEvoy KM. Treatment of Lambert-Eaton myasthenic syndrome. In: Lisak RP, ed. Handbook of myasthenia gravis and myasthenic syndromes. New York: Dekker, 1994:409-415.

18. Khatri BO, McQuillen MP, Harrington GJ, Schmoll D, Hoffmann RG. Chronic progressive multiple sclerosis: double-blind controlled study of plasmapheresis in patients taking immunosuppressive drugs. Neurology 1985;35:312-319.

19. Weiner HL, Dau PC, Khatri BO, et al. Double-blind study of true vs. sham plasma exchange in patients treated with im. munosuppression of acute attacks of multiple sclerosis. Neurology 1989;39:1143-1149.

20. The Canadian Cooperative Multiple Sclerosis Study Group. The Canadian cooperative trial of cyclophosphamide and plasma exchange in progressive multiple sclerosis. Lancet $1991 ; 337: 441-446$.

Rodriguez M, Karnes WE, Bartleson JD, Pineda AA. Plasmapheresis in acute episodes of fulminant CNS inflammatory demyelination. Neurology 1993;43:1100-1104.

22. Lundberg A, Lilja LG, Lundberg PO, Try K. Heredopathia atactica polyneuritiformis (Refsum's disease): experiences of dietary treatment and plasmapheresis. Eur Neurol 1972;8: 309-324.

23. Kanter DS, Horensky D, Sperling RA, Kaplan JD, Malachowski ME, Churchill WH, Jr. Plasmapheresis in fulminant acute disseminated encephalomyelitis. Neurology 1995;45: 824-827.

24. Sinha S, Newsom-Davis J, Mills K, Byrne N, Lang B, Vincent A. Autoimmune aetiology for acquired neuromyotonia (Isaacs' syndrome). Lancet 1991;338:75-77.

25. Brashear HR, Phillips LH. Autoantibodies to GABAergic neurons and response to plasmapheresis in stiff-man syndrome. Neurology 1991;41:1588-1592.

26. Agnello-Dimitrijevic W, Moore PM. Plasmapheresis in CNSSLE [abstract]. Neurology 1994;44 (suppl 2):A276-A277.

27. L'Abbate A, Paciucci A, Bartolomeo F, et al. Selective removal of plasma cryoglobulins in cryoglobulinaemia. Proc Eur Dial Transplant Assoc 1977;14:486-494.

28. Berkman EM, Orlin JB. Use of plasmapheresis and partial plasma exchange in the management of patients with cryoglobulinemia. Transfusion 1980;20:171-178.

29. Betourne C, Buge A, Dechy H, Dorra M, Dournon E, Rancurel G. Neuropathies peripheriques au cours d'un myelome a IgA et d'une cryoglobulinemie mixte: traitement par plasmaphereses iteratives. Nouv Presse Med 1980;9:1369-1371.

30. Chad D, Pariser K, Bradley WG, Adelman LS, Pinn VW. The pathogenesis of cryoglobulinemic neuropathy. Neurology 1982;32:725-729.

31. Ginder PA, Middendorf DF, Abdou NI. Pancytopenia with mixed cryoglobulinemia: evidence for anti-precursor cell activity of cryoglobulin-effects of plasmapheresis. J Clin Immunol $1982 ; 2: 55-58$.

32. Malchesky PS, Clough JD. Cryoimmunoglobulins: properties, prevalence in disease, and removal. Cleve Clin Quart 1985;52: 175-192.

33. Graus F, Vega F, Delattre JY, et al. Plasmapheresis and antineoplastic treatment in CNS paraneoplastic syndromes with antineuronal autoantibodies. Neurology 1992;42:536-540. 


\title{
Neurology
}

\author{
Assessment of plasmapheresis [RETIRED] \\ Neurology 1996;47;840-843 \\ DOI 10.1212/WNL.47.3.840
}

This information is current as of September 1, 1996

Updated Information \& Services

Citations

Permissions \& Licensing

Reprints including high resolution figures, can be found at: http://n.neurology.org/content/47/3/840.full

This article has been cited by 4 HighWire-hosted articles: http://n.neurology.org/content/47/3/840.full\#\#otherarticles

Information about reproducing this article in parts (figures,tables) or in its entirety can be found online at:

http://www.neurology.org/about/about_the_journal\#permissions

Information about ordering reprints can be found online:

http://n.neurology.org/subscribers/advertise

Neurology ${ }^{\circledR}$ is the official journal of the American Academy of Neurology. Published continuously since 1951, it is now a weekly with 48 issues per year. Copyright Copyright 1996 by Advanstar Communications Inc.. All rights reserved. Print ISSN: 0028-3878. Online ISSN: 1526-632X.

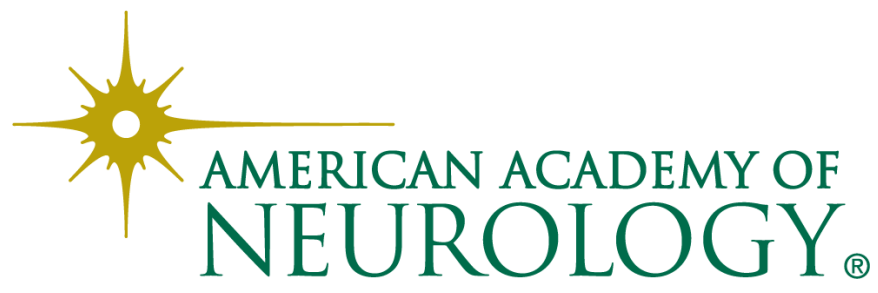

